\title{
Author Correction: Structural basis of indisulam-mediated RBM39 recruitment to DCAF15 E3 ligase complex
}

Dirksen E. Bussiere @i , Lili Xie @D, Honnappa Srinivas, Wei Shu, Ashley Burke, Celine Be, Junping Zhao, Adarsh Godbole, Dan King, Rajeshri G. Karki @, Viktor Hornak (D), Fangmin Xu, Jennifer Cobb, Nathalie Carte, Andreas O. Frank, Alexandra Frommlet (D), Patrick Graff, Mark Knapp, Aleem Fazal@B, Barun Okram, Songchun Jiang, Pierre-Yves Michellys, Rohan Beckwith (1), Hans Voshol, Christian Wiesmann, Jonathan M. Solomon (iD) and Joshiawa Paulk (1)

Correction to Nature Chemical Biology https://doi.org/10.1038/s41589-019-0411-6, published online 9 December 2019.

In the version of this article originally published, there were several typographical errors. In the second paragraph of Results section 'Purification and characterization of DCAF15 complexes', 'magnetic' and 'DDB1' were spelled incorrectly in the sentence beginning 'This weak interaction'. The sentence should read 'This weak interaction was confirmed by ${ }^{1} \mathrm{H}$ saturation transfer difference (STD) nuclear magnetic resonance (NMR), where STD peaks for indisulam were only detected in the presence of 1 $\mu$ M DCAF15-DDB1DDA1 (Supplementary Fig. 3)'. Furthermore, in the Methods section 'NMR Spectroscopy', 'pH 7.4' should read 'pD 7.4', '0.33 p.p.m.' should read ' -0.33 p.p.m.' and 'the number of points recorded was 32,000' should read 'the number of points recorded was 32,768'. The errors have been corrected in the HTML and PDF versions of the paper.

Published online: 15 January 2020

https://doi.org/10.1038/s41589-020-0471-7

(c) The Author(s), under exclusive licence to Springer Nature America, Inc. 2020 